\title{
A legislação brasileira e as recomendações internacionais sobre a exposição ocupacional aos agentes biológicos
}

Brazilian legislation and the international recommendations related to the occupational exposure to biologic agents La legislación brasilera y las recomendaciones internacionales acerca de la exposición ocupacional a los agentes biológicos

\section{Tanyse Galon', Maria Helena Palucci Marziale', Wecksley Leonardo de Souza'}

'Universidade de São Paulo. Escola de Enfermagem de Ribeirão Preto, Ribeirão Preto, SP

Submissão: 29/07/2009

Aprovação: 19/06/2010

\section{RESUMO}

Revisão bibliográfica cujo objetivo foi identificar a legislação brasileira relacionada à exposição ocupacional a material biológico entre os trabalhadores de saúde e compará-la com as principais recomendações da Organização Internacional do Trabalho (OIT) e do Centers for Disease Control and Prevention (CDC). A busca de informações se deu por acesso aos sites do Ministério da Saúde, Ministério do Trabalho e Emprego, OIT e CDC. Os dados coletados foram categorizados em cinco temas para melhor compreensão e análise. Identifica-se Que a legislação brasileira contempla grande parte das recomendações internacionais, porém a obrigatoriedade do fornecimento de dispositivos de segurança foi tardiamente incluída na legislação. Conclui-se Que os trabalhadores precisam obter informações sobre seus direitos e deveres frente à exposição ao risco biológico.

Descritores: Acidentes de trabalho; Exposição a agentes biológicos; Legislação como assunto; Enfermagem do trabalho.

\section{ABSTRACT}

Bibliographic review with the objective to identify the Brazilian legislation related to occupational exposure of health workers to biological material and compare it with the main recommendations of the International Labor Organization (ILO) and the Centers for Disease Control and Prevention (CDC). The information was searched by access to the websites of the Ministry of Health, Ministry of Labor and Employment, ILO and CDC. The data collected were categorized into five themes for better understanding and analysis. We find that the Brazilian legislation covers most of the international recommendations, but the obligation of providing safety devices was later included in the legislation. It is concluded that workers need information about their rights and duties before the exposure to biological hazards.

Key words: Occupacional accidents; Exposure to biological agents; Legislation as topic; Occupational health nursing.

\section{RESUMEN}

Estudio bibliográfico con objetivo de identificar la legislación brasileña en relación con la exposición ocupacional de los trabajadores de la salud a material biológico y compararla con las principales recomendaciones de la Organización Internacional del Trabajo (OIT) y lo Centers for Disease Control and Prevention (CDC). La búsqueda de información fue por el acceso a los sites del Ministerio de Salud, Ministerio de Trabajo y Empleo, la OIT y lo CDC. Los datos recogidos se clasificaron en cinco temas para una mejor comprensión y análisis. La legislación brasileña cubre la mayoría de las recomendaciones internacionales, pero la obligación de proporcionar los dispositivos de seguridad se incluyó más tarde en la legislación. Se concluye que los trabajadores necesitan información acerca de sus derechos y deberes ante la exposición a riesgo biológico.

Descriptores: Accidentes de trabajo; Exposición a agentes biológicos; Legislación como asunto; Enfermería del trabajo.

AUTOR Tanyse Galon. Av. dos Bandeirantes, 3900. CEP 14040-030. Ribeirão Preto, SP.

CORRESPONDENTE_E-mail: tanysegalon@gmail.com 


\section{INTRODUÇÃO}

A relação trabalho/saúde ainda se deflagra como um paradigma atual, sendo objeto de constantes reflexões e transformações. O modelo da Saúde do Trabalhador no Brasil permanece em construção, trazendo uma nova e ampliada perspectiva do processo de trabalho. No entanto, mesmo com esforços existentes, ainda são alarmantes os registros de acidentes de trabalho e doenças profissionais no Brasil, com graves consequências para as vítimas e seus familiares, abalando a estrutura familiar nos aspectos emocionais, sociais e econômicos(l). Portanto, o modelo de Saúde do Trabalhador ainda apresenta um impacto de pouca visibilidade frente às injurias Que atingem a saúde dos trabalhadores advindas da complexidade do modo de produção e seus efeitos ${ }^{(2)}$.

As cargas de trabalho existentes (biológicas, físicas, Químicas, psíquicas, mecânicas, entre outras) geram processos de desgaste, e o risco biológico é o mais relacionado à prática dos profissionais de saúde, uma vez que os serviços de saúde são locais Que propiciam o constante contato com sangue ou outros fluídos orgânicos, conferindo a esses trabalhadores a possibilidade de adeuirirem doenças como as hepatites B e C e a Síndrome da Imunodeficiência AdQuirida (AIDS) ${ }^{(3-4)}$.

Contudo, além de saber dos riscos a Que está exposto no ambiente de trabalho, o trabalhador também precisa conhecer as legislações trabalhistas no sentido de identificar seus direitos e deveres e se integrar efetivamente no campo da Saúde do Trabalhador.

Na segunda metade da década de 1960, países industrializados como a Alemanha, França, Estados Unidos e Itália passaram por transformações nos modos de pensar, e em decorrência da mobilização dos trabalhadores, políticas sociais transformaram-se em leis, desencadeando mudanças na legislação do trabalho e nos aspectos da segurança e saúde do trabalhador ${ }^{(5)}$.

No Brasil houve, em 1904, uma tentativa de se criar uma legislação especial para acidentes causados pelo trabalho, porém sem resultados, visto Que os interesses políticos e econômicos do país estavam à frente das Questões relacionadas à saúde dos trabalhadores Foi em 1919 Que surgiu o primeiro decreto legislativo definindo o acidente de trabalho com característica unicausal. No entanto, somente a partir de 1987 Que as principais normas legais foram sendo ampliadas e desenvolvidas ${ }^{(6)}$.

A promulgação da Constituição Federal em 1988 permitiu um grande avanço na legislação trabalhista brasileira. A Saúde do Trabalhador passa a se inserir efetivamente no campo da saúde, incorporando-se dentro do Sistema Único de Saúde (SUS), cujas ações se constroem com base em seus princípios de universalidade, integralidade e participação social ${ }^{(7)}$.

A partir da lei magna, as exigências legais foram se transformando em portarias, leis e decretos, em Que espaços foram oportunizados ao trabalhador como agente integrante da situação de trabalho e participante das políticas sociais. Mesmo assim, a violação dos direitos trabalhistas é uma realidade no país, e muitos trabalhadores encontram-se alienados desses direitos, o Que intensifica a precariedade das condições de trabalho ${ }^{(8)}$.

Mediante a existência de um grande número de leis, a dificuldade de leitura e compreensão das normas, a falta de atenção para tal prática, e considerando Que a exposição aos agentes biológicos patogênicos representa uma importante forma de agravo à saúde dos trabalhadores da área da saúde, este estudo tem como objetivos:

- Identificar as leis nacionais Que regulamentam a segurança ocupacional dos profissionais de saúde, relacionada à prevenção do risco biológico;

- Comparar as leis nacionais com as recomendações da Organização Internacional do Trabalho (OIT) e do Centers for Disease Control and Prevention (CDC) Que abordam medidas preventivas frente ao risco biológico.

\section{MÉTODO}

O estudo foi desenvolvido com base no método dedutivo, utilizando-se o delineamento metodológico de pesquisa de revisão bibliográfica, Que teve como propósito reunir e sintetizar o conhecimento existente sobre o tema proposto. O levantamento dos dados foi realizado no período de agosto a dezembro de 2008 , por meio de consulta à legislação brasileira e às principais recomendações internacionais sobre o tema "saúde e segurança no trabalho dos profissionais de saúde frente ao risco biológico", por meio de acesso aos sites do Ministério do Trabalho e Emprego (MTE), Ministério da Saúde (MS), OIT e do CDC.

- Critérios de inclusão da legislação nacional: 1) leis Que abordam os aspectos saúde e segurança no trabalho e exposição a agentes biológicos patogênicos, aplicáveis aos profissionais de saúde; 2) publicadas em Qualouer período, atualizadas e até o momento válidas; 3) leis de alcance federal; 4) leis disponíveis na íntegra nos sites selecionados.

- Critérios de exclusão da legislação nacional: 1) leis Que fogem ao tema proposto; 2) desatualizadas ou revogadas; 3 ) leis estaduais ou municipais; 4) leis não disponíveis na íntegra nos sites selecionados.

A busca de dados relativa às recomendações internacionais foi realizada a partir da seleção das principais e mais recentes recomendações internacionais sobre a temática proposta, presentes nos sites da OIT e do CDC. A busca no site da OIT foi realizada através do acesso aos links Internacional Labour Standarts Homepage e Recommendation, sucessivamente. No site do CDC, acessou-se o link Health and Safety Topics e posteriormente os links Bloodbourne Infections Disease (HIV/AIDS e hepatitis B e C), Needlestick Injuries e Infection Control in Healthcare Settings. Foram incluídas as recomendações relacionadas ao objeto de estudo, descritas nos idiomas inglês e/ou espanhol, e disponíveis na íntegra.

Análise dos dados: as informações apresentadas nas leis nacionais e nas recomendações internacionais foram categorizadas, para descrição e comparação, segundo os seguintes temas: "função dos empregadores", "função dos trabalhadores", "medidas de proteção materiais e ambientais", "vigilância/fiscalização" e "treinamento/ capacitação".

\section{RESULTADOS E DISCUSSÃO}

Foram encontradas 12 leis nacionais Que regulamentam a saúde e a segurança ocupacional relacionadas aos agentes biológicos e aos trabalhadores de saúde, representadas no Quadro I.

A maioria das leis brasileiras Que regulamentam a saúde e segurança ocupacional é apresentada na forma de Normas 


\begin{tabular}{|c|c|c|c|}
\hline Título & Última Atualização & Ementa & Fonte \\
\hline $\begin{array}{l}\text { Portaria } n^{\circ} 3.214 \text { de } 08 \text { de junho de } \\
1978\end{array}$ & $\begin{array}{l}\text { Portaria SIT n }{ }^{\circ} \text { 17, de } 01 \text { de agosto } \\
\text { de } 2007\end{array}$ & $\begin{array}{l}\text { Norma Regulamentadora (NR) } 4 \text { - Serviços } \\
\text { Especializados em Engenharia de Segurança } \\
\text { e em Medicina do Trabalho (SESMT) }\end{array}$ & MTE \\
\hline $\begin{array}{l}\text { Portaria no } 3.214 \text { de } 08 \text { de junho de } \\
1978\end{array}$ & $\begin{array}{l}\text { Portaria SIT no 16, de } 10 \text { de maio } \\
\text { de 200I }\end{array}$ & $\begin{array}{l}\text { NR } 5 \text { - Comissão Interna de Prevenção de } \\
\text { Acidentes de Trabalho (CIPA) }\end{array}$ & MTE \\
\hline $\begin{array}{l}\text { Portaria no } 3.214 \text { de } 08 \text { de junho de } \\
1978\end{array}$ & $\begin{array}{l}\text { Portaria no } 194 \text {, de } 22 \text { de } \\
\text { dezembro de } 2006\end{array}$ & NR 6 - Equipamentos de Proteção Individual- EPI & MTE \\
\hline $\begin{array}{l}\text { Portaria no } 3.214 \text { de } 08 \text { de junho de } \\
1978\end{array}$ & $\begin{array}{l}\text { Portaria SSST no 19, de } 09 \text { de abril } \\
\text { de } 1998\end{array}$ & $\begin{array}{l}\text { NR } 7 \text { - Programa de Controle Médico em Saúde } \\
\text { Ocupacional (PCMSO) }\end{array}$ & MTE \\
\hline $\begin{array}{l}\text { Portaria no } 3.214 \text { de } 08 \text { de junho de } \\
1978\end{array}$ & $\begin{array}{l}\text { Portaria SSST no } 25 \text {, de } 29 \text { de } \\
\text { dezembro de } 1994\end{array}$ & $\begin{array}{l}\text { NR } 9 \text { - Programa de Prevenção de Riscos } \\
\text { Ambientais (PPRA) }\end{array}$ & MTE \\
\hline $\begin{array}{l}\text { Portaria no } 3.214 \text { de } 08 \text { de junho de } \\
1978\end{array}$ & & NR 26 - Sinalização de Segurança. & MTE \\
\hline $\begin{array}{l}\text { Portaria no 2616/GM de } 12 \text { de maio de } \\
1998\end{array}$ & & $\begin{array}{l}\text { CClH - Comissão de Controle de Infecção } \\
\text { Hospitalar }\end{array}$ & MS \\
\hline $\begin{array}{l}\text { Portaria } n^{\circ} 1339 / \mathrm{GM} \text { de } 18 \text { de } \\
\text { novembro de } 1999\end{array}$ & & Lista de Doenças Relacionadas ao Trabalho & MS \\
\hline $\begin{array}{l}\text { Portaria } n^{\circ} 1679 / \mathrm{GM} \text { de } 19 \text { de setembro } \\
\text { de } 2002\end{array}$ & & $\begin{array}{l}\text { Dispõe sobre a estruturação da Rede Nacional de } \\
\text { Atenção Integral à Saúde do Trabalhador no } \\
\text { Sistema Único de Saúde (SUS) - RENAST e dá } \\
\text { outras providências }\end{array}$ & MS \\
\hline $\begin{array}{l}\text { Portaria no } 777 / G M \text { de } 28 \text { de abril de } \\
2004\end{array}$ & & $\begin{array}{l}\text { Dispõe sobre os procedimentos técnicos para a } \\
\text { notificação compulsória de agravos à saúde do } \\
\text { trabalhador em rede de serviços sentinela específica, } \\
\text { no SUS }\end{array}$ & MS \\
\hline $\begin{array}{l}\text { Resolução RDC n } 306 \text { de 07de } \\
\text { dezembro de } 2004\end{array}$ & & $\begin{array}{l}\text { Dispõe sobre o Regulamento Técnico para o } \\
\text { gerenciamento de resíduos de serviços de saúde }\end{array}$ & MS \\
\hline $\begin{array}{l}\text { Portaria GM no } 485 \text { de } 11 \text { de novembro } \\
\text { de } 2005\end{array}$ & $\begin{array}{l}\text { Portaria no } 939 \text {, de } 18 \text { de } \\
\text { novembro de } 2008\end{array}$ & $\begin{array}{l}\text { NR } 32 \text { - Segurança e Saúde no Trabalho em } \\
\text { Serviços de Saúde }\end{array}$ & MTE \\
\hline
\end{tabular}

\section{Quadro 1. Leis nacionais Que regulamentam a saúde e a segurança ocupacional dos profissionais de saúde frente ao risco biológico.}

Regulamentadoras (NRs), aprovadas pela Portaria $\mathrm{n}^{\circ} 3.214$, de 08 de junho de $1978^{(9)}$.

A NR $4^{(10)}$ define o SESMT, cuja finalidade é promover a saúde e proteger a integridade do trabalhador no ambiente laboral, com a atuação de profissionais especializados.

O PPRA ${ }^{(1)}$ atua através da antecipação, reconhecimento, avaliação e controle dos riscos ambientais Que existem ou Que possam existir no ambiente de trabalho, visando a preservação da saúde dos profissionais. O $\mathrm{PCMSO}^{(12)}$ tem suas ações focalizadas no trabalhador, contemplando desde a avaliação dos riscos até as medidas necessárias frente aos mesmos.

$\mathrm{A} \mathrm{CIPA}^{(13)}$ tem como objetivo a prevenção de acidentes e doenças decorrentes do trabalho, e suas ações envolvem a elaboração do Mapa de Riscos e a organização anual da Semana Interna de Prevenção de Acidentes de Trabalho - SIPAT, além de outras medidas realizadas em conjunto com o SESMT.

A NR $26^{(14)}$ estabelece a sinalização de segurança Que deve ser usada no ambiente de trabalho para indicar diferentes locais/riscos, no sentido de prevenir a ocorrência de acidentes. Os EPIs são dispositivos usados pelo trabalhador como uma dentre várias medidas de proteção da saúde no ambiente laboral e as recomendações de uso são ditadas pela NR $6^{(15)}$.

A NR 32 define diretrizes específicas sobre saúde e segurança no trabalho, profissionais da saúde e risco biológico em uma única norma, facilitando o acesso desses trabalhadores às preconizações
Que lhe são pertinentes ${ }^{(16)}$.

A Portaria $n^{\circ} 2616$ define as diretrizes para a prevenção e o controle das infecções hospitalares, Que podem causar danos tanto aos pacientes como aos próprios trabalhadores ${ }^{(17)}$. O manejo dos resíduos dos serviços de saúde é estabelecido pela Agência de Vigilância Sanitária - ANVISA através da Resolução n 306, cuja aplicação pode prevenir injúrias aos pacientes e profissionais de saúde $^{(18)}$.

A Lista de Doenças Relacionadas ao Trabalho ${ }^{(19)}$ foi novamente editada em 1990 e através dessa listagem é possível definir o perfil nosológico, ou perfil das moléstias da população trabalhadora, no sentido de estabelecer políticas públicas no campo da saúde do trabalhador.

A portaria $n^{\circ} 777$ de $2004^{(20)}$ regulamenta a notificação compulsória de agravos à saúde do trabalhador, e dentro desses agravos ela inclui os acidentes com exposição a material biológico, definindo um instrumento de notificação específico para esse tipo de acidente, o que possibilita conhecer as características dessas ocorrências e promover ações preventivas.

A Rede Nacional de Atenção Integral à Saúde do Trabalhador RENAST foi criada para promover ações em saúde do trabalhador Que abordam a vigilância e a assistência integral à saúde, independentemente do vínculo empregatício e do tipo de inserção no mercado de trabalho, o Que representa um avanço se comparado com as outras normas identificadas ${ }^{(21)}$. 
Diante do conteúdo abordado na legislação brasileira, passamos, a seguir, a compará-la às recomendações internacionais. Os dados foram agrupados em cinco temas para melhor compreensão das informações.

\section{Função dos empregadores}

As normas nacionais e internacionais definem funções Que envolvem adaptação do ambiente de trabalho, mudança das práticas e comportamento dos trabalhadores, fornecimento gratuito de materiais e eQuipamentos seguros, assistência médica, capacitação e vigilância.

A Resolução RDC n³ 306 e a NR 32 definem Que os empregadores devem disponibilizar meios para descarte, transporte, armazenamento e disposição final dos resíduos biológicos, além da capacitação dos trabalhadores no manejo destes ${ }^{(16,18)}$. A Recomendação da OIT $n^{\circ} 97^{(22)}$ também trata desse aspecto, preconizando que o empregador deve adotar medidas para Que os resíduos não se acumulem, constituindo um risco para a saúde no ambiente de trabalho.

A NR 32 preconiza Que os empregadores devem vedar a utilização de pias de trabalho para outros fins não previstos, a proibição do ato de fumar, do uso de adornos e lentes de contato e do consumo de alimentos e bebidas nos postos de trabalho ${ }^{(16)}$. Essas medidas, estabelecidas em 2005 no Brasil, já haviam sido preconizadas em 1992, pela Lei Bloodborne Pathogens Standard, nos Estados Unidos ${ }^{(23)}$.

A NR 7 estabelece Que o empregador deve custear o atendimento médico, a solicitação de exames laboratoriais, a imunização do trabalhador e principalmente toda a assistência após a ocorrência de acidente relacionado à exposição a material biológico ${ }^{(12)}$. Além disso, a OIT também define que o empregador deve prever medidas para atuar frente a situações de urgência e emergência, proporcionando primeiros auxílios sem custo ao empregado ${ }^{(24)}$.

A obrigação do empregador de disponibilizar EPI aprovado por órgão competente, sem custo para o trabalhador, e de substituí-lo sempre Que danificado ou extraviado, é definida pela NR 6 e NR $32^{(15-16)}$. A OIT acrescenta Que o EPI não deve substituir a busca pela eliminação ou redução da exposição aos agentes biológicos patogênicos e pelas medidas ambientais e coletivas ${ }^{(24)}$.

Para o CDC, os materiais pérfuro-cortantes com dispositivo de segurança, como agulhas retráteis, são de fundamental importância na redução dos acidentes de trabalho e os empregadores devem avaliá-los e implementá-los ${ }^{(25)}$. No Brasil isso foi preconizado em 2005 pela NR 32 e pela Portaria n 939 em $2008^{(26)}$, portanto o país necessita aplicar essa medida cuja eficiência e eficácia já foram comprovadas.

A OIT responsabiliza os empregadores Quanto à capacitação dos trabalhadores, indicando Que ela deve ser contínua e sem custo $^{(24)}$, e o CDC recomenda Que a educação em saúde seja transmitida de forma clara, objetiva e de fácil acesso aos profissionais de saúde ${ }^{(25)}$. A NR 32 exige a capacitação dos trabalhadores antes do início das atividades e de forma continuada ${ }^{(16)}$.

Os empregadores, segundo a OIT, devem assegurar a vigilância, a avaliação e a inspeção periódica do ambiente de trabalho ${ }^{(24)}$. A NR 32 define Que o empregador deve informar imediatamente aos trabalhadores e aos seus representantes QualQuer acidente ou incidente grave Que possa provocar disseminação de um agente biológico suscetível de causar doenças graves nos seres humanos, definindo as suas causas e as medidas Que serão adotadas para corrigir a situação $0^{(16)}$.

As funções dos empregadores preconizadas nas leis brasileiras assemelham-se a várias normas internacionais. No entanto, a dificuldade Que se observa no país é a falta de integração entre os empregadores e os trabalhadores nas ações preventivas. A OIT preconiza Que os empregadores têm a obrigação de consultar os trabalhadores e cooperar com eles, um elemento essencial das medidas organizativas para cumprir as normas e promover a saúde no ambiente de trabalho ${ }^{(24)}$.

Também no sentido de promover integração, a OIT define Que, para os países em desenvolvimento, é prioridade promover um enfoque de sistemas de gestão de segurança e saúde do trabalho, no Qual haja a troca de informações entre os países e sejam abordadas as limitações dos empregadores frente às exigências legais (27), visto Que o não cumprimento das normas também pode relacionar-se a dificuldades políticas, econômicas e organizacionais desses empregadores.

\section{Função dos trabalhadores}

Normas nacionais definem Que os deveres dos trabalhadores frente aos riscos biológicos envolvem basicamente o uso de EPIs ${ }^{(15-}$ ${ }^{16)}$, o correto descarte dos materiais pérfuro-cortantes ${ }^{(20)}$, o não re-encape de agulhas ${ }^{(16)}$, a redução e o correto manejo dos resíduos biológicos ${ }^{(16,18)}$, a lavagem das mãos antes e depois de QualQuer procedimento $^{(16-17)}$, a notificação e tratamento médico após acidente de trabalho ${ }^{(12,20)}$ e a imunização $0^{(12,16)}$.

O uso de EPIs pelos trabalhadores é também definido em várias recomendações da OIT $^{(22.28-29)}$, nas Quais é mencionada a importância do uso desses equipamentos para a proteção do trabalhador. O CDC também trata desse aspecto, definindo Que para prevenir os acidentes, é necessário o uso apropriado de barreiras, como luvas e óculos de proteção ${ }^{(23)}$.

A responsabilidade do profissional de saúde em descartar corretamente os objetos pérfuro-cortantes, bem como sua obrigação de não re-encapar agulhas ou desconectá-las manualmente, é preconizada no Brasil pela NR 32 e também pelo CDC em suas recomendações mais atuais ${ }^{(25)}$.

A importância do manejo correto dos resíduos e da adoção de medidas para prevenção da infecção hospitalar, como lavagem das mãos, é recomendada pelo $\mathrm{CDC}^{(30)}$. As NRs 7 e 32 e norma americana $^{(23)}$ estabelecem Que o trabalhador receba as vacinas disponíveis, notifique a ocorrência de acidentes de trabalho, Que se submeta a exames médicos necessários e que siga corretamente o tratamento prescrito, sendo informado sobre suas conseQüências positivas e negativas $^{(23)}$.

Apesar das leis brasileiras cumprirem teoricamente com várias recomendações internacionais, identifica-se no Brasil Que o cotidiano da maioria dos serviços de saúde pouco representa um cenário de cumprimento dessas normas. Quando há equipamentos e condições ambientais seguras para os trabalhadores, o fator "tempo" e as pressões da chefia, da equipe e da demanda impedem que o trabalhador preze sua saúde e bem-estar, em detrimento das responsabilidades do cuidado a um grande número de pacientes ${ }^{(3)}$.

Para o CDC, além de todas as medidas citadas, é preciso Que haja uma equipe adequada à proporção de pacientes ${ }^{(25)}$. Essa 
afirmação aponta para a importância de mudanças organizacionais do trabalho e a necessidade de recursos humanos, e não só da criação de normas e leis.

A NR 9 define Que os trabalhadores devem informar ao superior hierárquico ocorrências Que a seu ver representam riscos à saúde no trabalho(11). Essa norma nacional é compatível com a

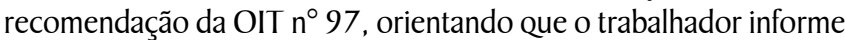
à chefia QualQuer situação Que possa causar algum dano Que eles mesmos não podem solucionar ${ }^{(22)}$, e assemelha-se também à recomendação $n^{\circ} 164$, definindo Que as informações dos trabalhadores devem ser reconhecidas ${ }^{(28)}$.

No entanto, enquanto as leis definem Que o conhecimento e a percepção dos trabalhadores sobre o processo de trabalho devem ser considerados, identifica-se no país Que a classe trabalhadora é isolada dessas Questões, o Que intensifica ainda mais a alienação do trabalhador ${ }^{(29)}$.

A OIT, ao analisar a aplicação prática das normas sobre saúde e segurança no trabalho por vários países, identificou Que existe um fracasso em assegurar o direito dos trabalhadores de interromper seu trabalho Quando vêem Que existe um perigo grave e iminente ${ }^{(24)}$. Os meios de participação e voz dos trabalhadores, como os sindicatos e outras organizações, precisam ser ativados com objetivos conjuntos para Que mudanças concretas sejam feitas. A única maneira de se conseguir um trabalho decente em condições de liberdade, igualdade e dignidade humana é que os profissionais de saúde tenham a oportunidade de expressar-se sobre o que estes conceitos significam para a sua Qualidade de vida.

\section{Medidas de proteção materiais e ambientais}

Para a norma americana Bloodborne Pathogens Standard e posteriormente para a NR 32, é obrigatória a existência de lavatório exclusivo para higiene das mãos, com água corrente, torneiras ou comandos Que dispensem a abertura manual, sabonete lípuido, toalha descartável e lixeira com sistema de abertura sem contato das mãos ${ }^{(16,23)}$.

De acordo com a NR 26, a cor verde caracteriza "segurança" e deve ser empregada para identificar fontes lavadoras de olhos, Quadro para exposição de cartazes, boletins ou avisos de segurança, e localização de EPIs e dispositivos de segurança ${ }^{(14)}$. Como padronização internacional, o risco biológico é representado por um símbolo na cor laranja, com a descrição Biohazard ou "risco biológico"(23). A CIPA também atua nesse aspecto, definindo o mapa de riscos dentro dos serviços de saúde, no Qual a presença do risco biológico é representada pela cor vinho ${ }^{(13)}$.

Segundo norma internacional, luvas de diferentes tamanhos, hipoalérgicas ou sem talco devem estar disponíveis aos trabalhadores ${ }^{(25)}$, o Que não é descrito em nenhuma norma nacional. Quando as luvas são fornecidas, não existem variedades nos tamanhos e tipos de produtos. Um estudo identificou que um dos motivos para não usá-las durante a punção venosa é a inadeQuada adaptação da luva ao profissional, seja no tamanho, na Qualidade do material ou na perda de sensibilidade tátil. Portanto não basta prover o EPI se ele não estiver adaptado àQueles que o utilizam ${ }^{(30)}$.

As agulhas e seringas com dispositivos de segurança devem possuir uma capa rígida Que não permita o contato direto das mãos com a agulha; garantir segurança durante todo o processo de manuseio; ter uma operação simples e óbvia; ter um custo o mais reduzido possível; e acima de tudo, Que esses dispositivos não comprometam a integridade do trabalhador e a do paciente ${ }^{(25)}$.

Segundo o CDC, no início da década de 80 as medidas de prevenção incluíam programas de educação, o não re-encape de agulhas, e melhores dispositivos de agulhas. Entre 1987 e 1991 as ações tinham como foco a utilização de coletores de pérfurocortantes mais rígidos e resistentes e informações aos trabalhadores Quanto ao perigo de re-encapar ou Quebrar as agulhas ${ }^{(25)}$.

As precauções universais foram importantes na redução do número de acidentes percutâneos, contudo o uso de luvas, óculos e máscaras por si só não representava um grande impacto na prevenção desses acidentes. Afinal, esses EPIs até protegem o trabalhador contra o contato com sangue e outros fluidos corpóreos como pele e mucosa, mas as agulhas e outros objetos pérfurocortantes podem facilmente penetrar essas barreiras ${ }^{(25)}$.

As medidas mais atuais de prevenção seguem uma "hierarquia de controle". A prioridade é eliminar ou reduzir o uso de agulhas e outros objetos pérfuro-cortantes ao máximo possível, e após isso, usar todos os métodos de controle de engenharia, como os dispositivos de segurança. Por fim, se essas estratégias não provêm total proteção do trabalhador, então são adotados o controle das práticas de trabalho (não re-encapar agulhas, recipientes de descartes rígidos) e o uso de $\mathrm{EPIs}^{(25)}$.

Nas pesquisas que realizamos junto à Rede de Prevenção de Acidentes de Trabalho - REPAT/USP(31), Que estuda as características dos acidentes de trabalho com exposição a material biológico em hospitais brasileiros, identificamos Que, mesmo após a implantação da NR 32, ainda persiste o manuseio excessivo de material pérfurocortante e o não uso de agulhas com dispositivos de segurança, além da concepção de Que o fornecimento de EPIs é prioridade para a proteção do trabalhador. $\mathrm{O}$ adoecimento do trabalhador frente ao risco biológico ainda é visto como algo inerente aos profissionais da saúde, prevalecendo concepções mais curativas do Que preventivas. Torna-se necessário promover o acesso dos serviços de saúde a novas tecnologias e novas propostas Que priorizem mais a prevenção do Que somente a notificação e a assistência do trabalhador Quando a exposição e a contaminação já ocorreram.

\section{Vigilância/Fiscalização}

Inseridas na ampla e complexa definição de vigilância à saúde do trabalhador, existem dois aspectos fundamentais Que apresentam dificuldades em sua aplicação: a inspeção do ambiente de trabalho e as estatísticas dos acidentes de trabalho.

Para a OIT, de acordo com a Recomendação $n^{\circ}$ 171, uma das ações de vigilância do ambiente de trabalho envolve as visitas de profissionais Qualificados em saúde e segurança para examinar o local e as condições laborais, com o objetivo de detectar precocemente QualQuer alteração Que possa causar danos à saúde dos trabalhadores ${ }^{(32)}$. Entretanto, no Brasil, as leis identificadas pouco enfocam essa ação na avaliação da saúde e segurança dos trabalhadores.

Partindo para a realidade dos serviços de saúde, a inspeção do trabalho manifesta-se como uma prática pontual e punitiva. A OIT detectou Que em vários países o principal papel dos serviços de inspeção, o de prezar pelo cumprimento das normas relativas às condições de trabalho Que protejam a saúde dos trabalhadores, é 
substituído pelo papel de árbitros nos conflitos individuais e coletivos do trabalho ${ }^{(24)}$.

A OIT também identificou a dificuldade dos empregadores, trabalhadores e seus representantes de participar e ter acesso aos resultados da inspeção do trabalho, fato Que os impede de compreender, opinar e efetivar o cumprimento das normas ${ }^{(24)}$. O temor dos empregadores e trabalhadores frente à inspeção e a prática pontual e punitiva dos órgãos fiscalizadores devem ser substituídos pelo diálogo e pela busca de melhorias nas condições de trabalho.

Com relação às estatísticas dos acidentes e doenças relacionadas ao trabalho, a OIT e o CDC as consideram medidas básicas e essenciais para o desenvolvimento de estratégias de prevenção dos acidentes de trabalho. A OIT recomenda a necessidade do intercâmbio de dados estatísticos sobre segurança e saúde no trabalho entre as autoridades competentes, os empregadores, os trabalhadores e seus representantes $^{(32)}$ e o CDC relata Que os dados sobre os casos de acidentes com pérfuro-cortantes são essenciais para caracterizar Quem, onde, Quando e como esses eventos ocorrem ${ }^{(25)}$.

Contudo, verifica-se no Brasil a escassez de informações sobre os acidentes de trabalho. A real magnitude do problema é difícil de ser mensurada devido à pouca informação com relação aos trabalhadores de outros setores Que não o hospitalar, como clínicas particulares e atendimento domiciliar, além da existência da subnotificação dos acidentes ${ }^{(25)}$.

No sentido de mudar essa situação, o Brasil vem avançando através de várias medidas desenvolvidas no plano legal, como a revisão anual obrigatória da Lista de Doenças Relacionadas ao Trabalho, a criação da RENAST e a construção da portaria $n^{\circ} 777$ pelo Ministério da Saúde. Essas leis possibilitam que Qualquer trabalhador, formal ou informal, notifieue a ocorrência de acidente de trabalho (Notificação Compulsória) e receba acolhimento e atenção integral à sua saúde, por meio da rede de serviços sentinela específica, Que compreendem serviços selecionados da rede de Atenção Básica, os Centros de Referência em Saúde do Trabalhador - CEREST, e a rede assistencial de média e alta complexidade do SUS ${ }^{(19-21)}$.

Os acidentes de trabalho com exposição a material biológico são considerados agravos de notificação compulsória, e já existe, além do Comunicado de Acidente de Trabalho - CAT, o SINAN Sistema Nacional de Agravos de Notificação, uma ficha on-line Que permite reunir informações de todo o país. Além da criação desse sistema nacional de informação, é preciso Que os empregadores e os trabalhadores estejam conscientes da necessidade de notificar os acidentes, Que tenham acesso ao SINAN dentro dos serviços de saúde e Que estejam capacitados para utilizá-lo.

\section{Treinamento/Capacitação}

A NR 32 define Que a capacitação do trabalhador deve ser ministrada sempre Que ocorram mudanças nas condições de exposição dos trabalhadores aos agentes biológicos patogênicos, durante a jornada de trabalho e por profissionais familiarizados com a temática. Essa capacitação deve ser comprovada através de documentos Que informem a data, a carga horária, o conteúdo ministrado, o nome e a formação ou capacitação profissional do instrutor e dos trabalhadores envolvidos ${ }^{(16)}$.

A NR 5 define Que um dos temas Que deve ser abordado durante a capacitação são as legislações trabalhistas sobre segurança e saúde no trabalho, o Que também é recomendado na Bloodborne Pathogens Standard. A portaria $n^{\circ} 2616$ e o CDC preconizam a capacitação do Quadro de funcionários e profissionais da instituição, no Que diz respeito à prevenção e controle das infecções hospitalares (17.33). Essa norma internacional também orienta que as diretrizes e a educação em saúde devem ser transmitidas de forma objetiva, com linguagem clara, e de fácil acesso aos trabalhadores, o Que condiz com as diretrizes da NR 32.

A recomendação $n^{\circ} 171$ da OIT preconiza Que os serviços de saúde no trabalho devem participar da elaboração e aplicação de programas de informação e educação dos trabalhadores sobre medidas preventivas de adoecimento e acidentes de trabalho, e verifica-se pelas leis nacionais Que o SESMT e a CIPA tem como dever atuar nessas medidas de forma articulada.

A recomendação da OIT Sobre o Marco Promocional para a Saúde e Segurança no Trabalho traz uma concepção importante Que é a base para a efetivação das ações em saúde do trabalhador: a promoção de uma cultura nacional de prevenção em segurança e saúde no trabalho, na Qual todos os envolvidos, o Estado, os empregadores, os trabalhadores e toda a sociedade estejam informados e tenham interesse pela temática ${ }^{(27)}$. Para isso, o tema precisa ser abordado na formação profissional dos envolvidos, e os resultados dos estudos precisam ser amplamente divulgados dentro do cotidiano dos serviços de saúde, de uma forma Que alcance e produza resultados na saúde dos trabalhadores.

\section{CONCLUSÃO}

A legislação nacional contempla grande parte das recomendações internacionais, porém a implementação das recomendações ainda não foi efetivada em muitos serviços de saúde, por exemplo, com relação a não utilização de agulhas e seringas com dispositivos de segurança.

Embora a legislação nacional contemple os aspectos internacionalmente preconizados, identificam-se na prática lacunas na eficiência da fiscalização da adoção das recomendações de segurança nos locais de trabalho e uma inversão na concepção e nos métodos de prevenção e controle dos acidentes de trabalho, persistindo a idéia de risco inerente à determinada atividade, como se o risco biológico estivesse naturalmente presente e como se a exposição a esse risco fosse algo aceitável. Na realidade é importante considerar Que esses fatores existem por outros determinantes Que não a impossibilidade técnica de sua eliminação ou controle, e que na verdade eles são decorrentes da insuficiente valorização da saúde e da vida dos trabalhadores.

Apesar da existência de inúmeras formas de capacitação, é difícil introduzir informações e normas na mentalidade e na vida prática dos trabalhadores em um país onde, em matéria de saúde e segurança do trabalhador, há uma escassez de diálogo e troca de informações entre os grandes centros de pesquisa no assunto e os serviços de saúde. A evolução do conhecimento fica retida dentro das universidades, sendo objeto de discussão entre uma minoria intelectual, não alcançando os gestores dos serviços de saúde e, por conseguinte os trabalhadores e a sociedade.

Os valores individuais, as formações acadêmicas deficitárias, a neutralidade da sociedade, a insuficiente capacidade de pressão 
dos trabalhadores, a indiferença dos empregadores e a dificuldade de implementação de uma política efetiva, resultam no processo de adoecimento dos trabalhadores onde as leis são transformadas em documentos burocráticos. Portanto, é necessário não só o avanço da legislação, mas também das políticas públicas e da reivindicação dos trabalhadores.

\section{REFERÊNCIAS}

1. Pinho DLM, Rodrigues CM, Gomes GP. Perfil dos acidentes de trabalho no Hospital Universitário de Brasília. Rev Bras Enferm 2007; 60(3): 291-4.

2. Minayo-Gomes C, Lacaz FAC. Saúde do trabalhador: novas e velhas Questões. Ciênc Saúde Coletiva 2005; 10(4): 797-807.

3. Ribeiro EJG, Shimizu HE. Acidentes de trabalho com trabalhadores de enfermagem. Rev Bras Enferm 2007; 60(5): $535-40$.

4. Marziale MHP, Silva EI, Haas VI, Robazzi MLCC. Acidentes com material biológico em hospital da Rede de Prevenção de Acidentes de Trabalho - REPAT. Rev Bras Saúde Ocup 2007; 32 (115): 109-19.

5. Mendes R, Dias EC. Da medicina do trabalho à saúde do trabalhador. Rev Saúde Pública 199I; 25 (5): 34I-9.

6. Sarquis LMM, Cruz EBS, Hausmann M, Felli VEA, Peduzzi M. Uma reflexão sobre a saúde do trabalhador de enfermagem e os avanços da legislação trabalhista. Cogitare Enferm 2004; 9(1): 15-24

7. Ministério da Saúde (BR). Secretaria de Atenção à Saúde. Departamento de Ações Programáticas Estratégicas. Legislação em saúde: caderno de legislação em saúde do trabalhador. $2^{a}$ ed. Brasília: Ministério da Saúde; 2005

8. Lourenço EAS, Bertani IF. Saúde do trabalhador no SUS: desafios e perspectivas frente à precarização do trabalho. Rev Bras Saúde Ocup 2007; 32(115): 121-34

9. Ministério do Trabalho e Emprego (BR). Portaria no 3.214, de 08 de junho de 1978. Aprova as Normas Regulamentadoras NR - do Capítulo V, Título II, da Consolidação das Leis do Trabalho, relativas a Segurança e Medicina do Trabalho. Diário Oficial da União 1978 ago. [citado em 2008 Ago 25]. Disponível em: http://www.mte.gov.br/legislacao/portarias/ 1978/p_19780608_3214.pdf

10. Ministério do Trabalho e Emprego (BR). Portaria $n^{\circ} 17$ de I de agosto de 2007. Altera a redação da Norma Regulamentadora $n^{\circ}$ 4. Serviços Especializados de Segurança e Medicina do Trabalho. Diário Oficial da União 2007 ago. [citado em 2008 Ago 25]. Disponível em: http://www.mte.gov.br/legislacao/ normas regulamentadoras/nr_04a.pdf

11. Ministério do Trabalho e Emprego (BR). Portaria $\mathrm{n}^{\circ} 25$ de 29 de dezembro de 1994. Altera Norma regulamentadora $\mathrm{n}^{\circ} 9$. Programa de Prevenção de Riscos Ambientais. Diário Oficial da União 1994, dez. [citado em 2008 Ago 25]. Disponível em: http://www.mte.gov.br/legislacao/normas regulam entadoras/nr_09_at.pdf

12. Ministério do Trabalho e Emprego (BR). Secretaria de Segurança e Saúde no Trabalho. Portaria n ${ }^{\circ} 19$ de 9 de abril de 1998. Altera Norma Regulamentadora $n^{\circ} 7$. Programa de Controle Médico em Saúde Ocupacional. Diário Oficial da União 1998 abril. [citado em 2008 Ago 25]. Disponível em: http:// www.mte.gov.br/legislacao/normas regulamentadoras/ nr_07_at.pdf
13. Ministério do Trabalho e Emprego (BR). Portaria $\mathrm{n}^{\circ} 16$ de 10 de maio de 200l. NR5 - Comissão Interna de Prevenção de Acidentes de Trabalho. [citado em 2008 Ago 25]. Disponível em: http://www.mte.gov.br/legislacao/normas_regulamen tadoras/nr_05.pdf

14. Ministério do Trabalho e Emprego (BR). Portaria $\mathrm{n}^{\circ} 3.214$ de 8 de junho de 1978. NR26 - Sinalização de Segurança. [citado em 2008 Ago 25]. Disponível em: http://www.mte.gov.br/ legislacao/normas_regulamentadoras/nr_26.pdf

15. Ministério do Trabalho e Emprego (BR). Portaria n ${ }^{\circ} 194$ de 22 de dezembro de 2006. NR6 - Equipamentos de Proteção Individual. [citado em 2008 Ago 25]. Disponível em: http:// www.mte.gov.br/legislacao/normas_regulamentadoras/ nr_06.pdf

16. Ministério do Trabalho e Emprego (BR). Portaria no 485 de 1 I de novembro de 2005. NR32 - Segurança e Saúde no Trabalho em Serviços de Saúde. [citado em 2008 Ago 25]. Disponível em: http://www.mte.gov.br/legislacao/normas regulamentado ras/nr_32.pdf

17. Ministério da Saúde (BR). Portaria no 2.616 de 12 de maio de 1998. Dispõe sobre diretrizes e normas para a prevenção e o controle das infecções hospitalares. Diário Oficial da República Federativa da União 1998. [citado em 2008 Out 9]. Disponível em: http://e-legis.anvisa.gov.br/leisref/public/showAct. php?id $=482$

18. Ministério da Saúde (BR). Agência Nacional de Vigilância Sanitária. Resolução RDC n 306 de 7 de dezembro de 2004. Dispõe sobre o regulamento técnico para o gerenciamento de resíduos de serviços de saúde. [citado em 2008 Out 9]. Disponível em: http://e-legis.anvisa.gov.br/leisref/public/ showAct.php?id=13554

19. Ministério da Saúde (BR). Portaria ${ }^{\circ} 1339$ de 18 de novembro de 1999. Lista de Doenças Relacionadas ao Trabalho. [citado em 2008 Out 9]. Disponível em: http://dtr200 I saude.gov.br/ sas/PORTARIAS/Port99/GM/GM- I339.html

20. Ministério da Saúde (BR). Portaria $n^{\circ} 777$ de 28 de abril de 2004. Dispõe sobre os procedimentos técnicos para a notificação compulsória de agravos à saúde do trabalhador em rede de serviços sentinela específica, no Sistema único de Saúde. [citado em 2008 Out 9]. Disponível em: http:// dtr200 I.saude.gov.br/sas/PORTARIAS/Port2004/GM/GM777.htm

21. Ministério da Saúde (BR). Portaria n ${ }^{\circ} 1679$ de 19 de setembro de 2002. Dispõe sobre a estruturação da Rede Nacional de Atenção Integral à Saúde do Trabalhador no SUS - RENAST e dá outras providências. [citado em 2008 Out 9]. Disponível em: http://dtr200 I .saude.gov.br/sas/PORTARIAS/Port2002/ Gm/GM-1679.htm

22. Organización Internacional del Trabajo. Recomendación no 97 sobre la protección de la salud de los trabajadores. Ginebra, 1953. [citado em 2008 Nov 14]. Disponível em: http:// www.ilo.org/ilolex/spanish/recdisp I.htm 
23. Centers for Disease Control and Prevention (US).United States Department of Labor. Occupational Safety and Health Administration. Bloodborne Pathogens Standard (29 CFR 1910.1030). United States of America, 1991. [cited 2008 Dec 6]. Available from: http://www.cdc.gov/niosh/topics/bbp

24. Organización Internacional del Trabajo. Las Normas Internacionales del Trabajo: Un Enfoque Global. Ginebra, 2002. [citado em 2008 Nov 14]. Disponível em: http://www.ilo.org/ global/What_we_do/InternationalLabourStandards/ InformationResources/Publications/lang-es/docNameWCMS_087694/index.htm

25. Centers for Disease Control and Prevention (US). Department of Health and Human Services. Workbook for designing, implementing, and evaluating a sharps injury prevention program, United States of America 2008. [cited 2008 Dec 6]. Available from: http://www.cdc.gov/Sharpssafety/pdf/ sharpsworkbook_2008.pdf

26. Ministério do Trabalho e Emprego (BR). Portaria no 939, de 18 de novembro de 2008. Diário Oficial da União, 2008. [citado em 2008 Dez 2]. Disponível em: http://www.mte.gov.br/ legislacao/portarias/2008/p_20081 I I8_939.pdf

27. Organización Internacional del Trabajo. Recomendación $n^{\circ} 197$ sobre el marco promocional para la seguridad y salud en el trabajo. Ginebra, 2006. [citado em 2008 Nov 14]. Disponível em: http://www.ilo.org/ilolex/spanish/recdisp I .htm

28. Organización Internacional del Trabajo. Recomendación n 164 sobre seguridad y salud de los trabajadores. Ginebra, 1981. [citado em 2008 Nov 14]. Disponível em: http://www.ilo.org/ ilolex/spanish/recdisp I.htm

29. Canôas JW, organizador. Mundo do trabalho e políticas públicas. $I^{\circ}$ ed. Franca: Universidade Estadual Paulista (UNESP); 2007

30. Zapparoli AS, Marziale MHP, Robazzi MLCC. Práctica segura del uso de guantes em la puncion venosa por los trabajadores de enfermeria. Cienc Enferm 2006; 12(2): 63-72.

31. Rede de Prevenção de Acidentes de Trabalho. ede de Prevenção de Acidentes de Trabalho com Exposição à Material Biológico em Hospitais Universitários do Brasil. Ribeirão Preto: Universidade de São Paulo; 2008. [citado em 2008 Nov 15]. Disponível em: http://repat.eerp.usp.br

32. Organización Internacional del Trabajo. Recomendación $n^{\circ} 171$ sobre los servicios de salud en el trabajo. Ginebra, 1985. [citado em 2008 Nov 14]. Disponível em: http://www.ilo.org/ilolex/ spanish/recdisp I.htm

33. Centers for Disease Control and Prevention (US). Public Health Service. Department of Health and Human Services. Guideline for infection control in health care personnel. Whasington: CDC; 1998. [cited 2008 Dec 6]. Available from: http://www.cdc.gov/ ncidod/dhep/pdf/guidelines/InfectControl98.pdf 